East African Medical Journal Vol. 77 No. 2 February 2000

NATIONAL IMMUNISATION DAYS FOR POLIO ERADICATION IN UGANDA: DID IMMUNISATION CARDS INCREASE COVERAGE?

F. Nuwaha, MBChB, MPH, Department of Community Health, Mbarara University, P.O. Box 1410, Mbarara Uganda, E. Kabwongyera, MBChB, MMed, Senior Medical Officer, Uganda National Expanded Programme on Immunisation, Ministry of Health P.O. Box 8, Entebbe. G. Mulindwa MBChB, MA, Principal Health Planner, Ministry of Health, P.O. Box 8, Entebbe, Uganda and E. Barenzi, MSc, Programme Manager, Uganda National Expanded Programme on Immunisation, Ministry of Health, P.O. Box 8, Entebbe, Uganda

Request for reprints to: Dr. F. Nuwaha, P.O. Box 1410, Mbarara, Uganda

\title{
NATIONAL IMMUNISATION DAYS FOR POLIO ERADICATION IN UGANDA: DID IMMUNISATION CARDS INCREASE COVERAGE?
}

\author{
F. NUWAHA, E. KABWONGYERA, G. MULINDWA and E. BARENZI
}

\begin{abstract}
Objective: To analyse the effect of cards and of vitamin A supplementation on coverage for National Immunisation Days (NIDs).

Design: A retrospective ecological study.

Setting: A countrywide NIDs coverage before and after introduction of the NIDs cards and vitamin A supplementation in all districts of Uganda.

Methods: NIDs for polio eradication commenced in Uganda in 1996. Two rounds, one month apart are implemented yearly. During the second round of 1998 NIDs, cards were introduced nationally and vitamin supplementation was introduced in 24 of the 45 districts. We compared NIDs coverage before and after NIDs cards and NIDs coverage in districts that implemented vitamin $A$ to those that did not.

Results: After introduction of NIDs cards, the national coverage rose from $97.7 \%$ to $106.9 \%$, an increase of $9.2 \%$. In those districts that implemented vitamin A supplementation, the NIDs coverage rose from $100.1 \%$. to $111.5 \%$, an increase of $10.4 \%$. In those districts that did not implement vitamin A, the NIDs coverage rose by $6.7 \%$ from $94.5 \%$ to $102.2 \%$. Before the introduction of cards and vitamin $A$ in 1996 and 1997, the NIDs coverage was between 92-96\%.

Conclusion: NIDs cards and vitamin A supplementation could have increased the NIDs national coverage.
\end{abstract}

\section{INTRODUCTION}

The Global Polio Eradication Initiative (PEI) is already under way(1). As a result, Uganda started implementing National Immunisation Days (NIDs) in 1996 aimed at polio eradication. The NIDs supplement routine immunisation in general, and against polio, in particular. Two rounds of NIDs are carried out twice a year for all children under five years of age whether they have had polio immunisation before or not. The reported coverage for 1996 and 1997 NIDS was above $92 \%$ for the whole country for all the four rounds (2). However, much lower NIDS coverage of below $80 \%$ was recorded particularly in the districts of central Uganda. For example, whereas the national coverage for 1996 and 1997 were 96\%, 95\%, 92\% and $94 \%$ respectively, the coverage for the districts of central Uganda were: Kampala (55\%, 90\% 61\%, $68 \%$ ); Kiboga (70\%, $67 \%, 74 \%, 78 \%$,); Luwero $(55 \%, 71 \%$, $58 \%, 61 \%)$; Masaka (53\%, 65\%, 90, 80\%); Mpigi $(42 \%$, $47 \%, 56 \%, 58 \%)$; Mubende (82 \%, 77\%, $62 \%, 67 \%$ ); Mukono $(73 \%, 93 \%, 89 \%, 92 \%)$ and Rakai $(76 \%, 79 \%$, $65 \%, 69 \%)$. These low coverages are worrisome as they do not augur well for polio eradication. The reasons for these low coverages were not clearly explained, although the Ministry of Health attributed this to hostile media, de- campaigning by some opposition groups and fearing that the polio vaccine was contaminated with the human immunodeficiency virus (HIV). Clearly therefore, there was need for remedial action.

In a bid to increase NIDs coverage, NIDs cards were introduced in the second round of the 1998 NIDs for the whole country. Likewise the second round of NIDs in 1998 also saw the introduction of vitamin A supplementation alongside NIDs, in 24 districts. This study analyses whether or not the introduction of NIDs cards and or vitamin A supplementation increased the NIDs coverage.

\section{MATERIALS AND METHODS}

Study population and setting: Uganda has an estimated population of 20 million people spread over a land area of $197,100 \mathrm{~km}^{2}$. Children under the age of five years are estimated to be about four million. The majority of the population (about $80 \%$ ) are rural dwellers, whose main source of income is subsistence agriculture. The annual population growth rate is about $2.5 \%$. The national routine immunisation coverage for children under one year of age in 1997 was: 84\% for BCG, $60 \%$ for measles; $59 \%$ for OPV3 and 58\% for DPT3. During the same year, the TT2 coverage among pregnant women was $45 \%$, whereas among non-pregnant women the coverage was only 
eight per cent. The EPI immunisation coverage has been declining since 1994 and the reasons for which are not clear. Administratively, Uganda is divided into 45 districts, with varying population level and access to health and immunisation services. Six of the districts, namely, Nakasongola, Katakwi Adjumani, Busia, Sembabule, and Bugiri are new having been created after the second round of NIDs in 1997. There are also varying levels of immunisation coverage, ranging, for example from measles coverage as high as $99 \%$ in Kumi to a rock bottom of $17 \%$ in Iganga according to 1997 figure. For NIDs, the total number of immunisation posts used were 13,000 of which about $40 \%$ were also used for routine immunisation. Both routine immunisation and NIDs are the responsibility of the Uganda National Expanded Programme on Immunisation (UNEPI), of the Ministry of health that was launched in 1984.

Design: This was a retrospective ecological study that compared immunisation coverage before and after introduction of the NIDs cards. To elucidate whether other factors (such as implementation of vitamin A and or creation of new districts) may have been responsible for the changes, NIDs coverage in new districts was compared with coverage in the old districts and with the national average. Coverage in districts that implemented vitamin A supplementation was also compared with the national average and with those districts that did not implement vitamin A supplementation.

Comparing national yearly coverage: In order to analyse the effects of NIDs cards on the immunisation coverage, national NIDs coverage for the years 1996, 1997 and 1998 as well as changes in coverage between the first and second round were compared. Should there be an increase in the 1998 NIDs coverage, when the cards were introduced as compared to 1997 and 1996 coverages, then it would be reasonable to assume that the cards had a positive effect.

Comparing district coverage: In order to determine whether relative performance in terms of increased coverage was due to introduction of cards, districts were categorised into three groups, namely: those with coverage above $100 \%$, those between 80 and $100 \%$, and finally those below $80 \%$. By comparing the proportion of districts in each coverage category before and after introduction of cards, it would be possible to reveal whether or not the cards had an effect on district performance.

Statistical analysis: Where number of districts were used, statistical analysis was with the Yates corrected Chi-square and or Fisher's exact test that were used to compare the proportions. Statistical software Epi info version 6 was used in the analysis. Where target populations and percentage coverage were used for comparison, no measurers of statistical significance were done for two reasons. First, the study dealt with populations and not samples. Second, since the numbers involved, were very big most of the analysis would show spurious significance and any difference is bound to be statistically significant.

\section{RESULTS}

National coverage for NIDs: The national coverage of NIDs for the years 1996-98 is shown in, Table 1. For the year 1996 there was a decrease in coverage between the first and second round whereas for the year 1997, there was a slight increase. However, for the year 1998, there was a marked increase in coverage and for the first time the national coverage was more than $100 \%$.

Table 1

NIDs coverage in Uganda by year and round of NIDs

\begin{tabular}{lcccc}
\hline Year & $\begin{array}{c}\text { Target } \\
\text { Population }\end{array}$ & $\begin{array}{c}\text { Coverage(\%) } \\
\text { first round }\end{array}$ & $\begin{array}{c}\text { Coverage(\%) } \\
\text { second round }\end{array}$ & $\begin{array}{c}\text { Percentage } \\
\text { change }\end{array}$ \\
\hline 1996 & 3994067 & 96 & 95 & -1 \\
1997 & 4045381 & 92 & 94 & 2 \\
1998 & 4056800 & 97.7 & 106.9 & 9.2 \\
\hline
\end{tabular}

Source: UNEPI's reports, Ministry of Health, Uganda

NIDs coverage by district: The NIDs coverage by district is shown in Tables 2,3 and 4. Table 2 shows that there was an increase in districts with more than $100 \%$ coverage and a decrease in districts with coverage below $80 \%$ between the first and second round of NIDs 1998. In 1996 there was no change in the number of districts below $80 \%$ and the districts with at least $100 \%$ decreased. The changes for 1997, NIDs coverage by districts were lower than those for 1998. Table 3 further shows that the proportion of districts with increase in coverage between the first and second rounds was more marked for the year 1998 as compared to the years 1997 and 1996 (Chi-square for linear trend $=34.36 \mathrm{p}=0.000$ ). The difference in the districts with an increase of more than ten per cent was even more marked for the year 1998 than for the years 1997 and 1996. Table 4 shows the change in coverage between the first and second round of NIDs for 1998. It is interesting to note that some of the most marked increases were among the districts that performed poorly during the first round of NIDs 1998. During the first round eight districts recorded a coverage below $80 \%$, but during the second round only three districts recorded coverage below $80 \%$. Even among these three districts, the coverage had greatly improved.

Table 2

District coverage in NIDs in Uganda 1996-1998

\begin{tabular}{|c|c|c|c|c|c|c|c|}
\hline \multirow{2}{*}{$\begin{array}{l}\text { District } \\
\text { coverage } \\
(\%)\end{array}$} & $\begin{array}{l}1996 \\
\text { round one }\end{array}$ & $\begin{array}{c}1996 \\
\text { round two }\end{array}$ & $\begin{array}{l}1997 \\
\text { round one }\end{array}$ & $\begin{array}{c}1997 \\
\text { round two }\end{array}$ & $\begin{array}{c}1998 \\
\text { round one }\end{array}$ & \multicolumn{2}{|c|}{$\begin{array}{c}1998 \\
\text { round two }\end{array}$} \\
\hline & No. $(\%)$ & No. $(\%)$ & No. $(\%)$ & No. $(\%)$ & No. $(\%)$ & No. & $(\%)$ \\
\hline$>100$ & $24 \quad(61)$ & $20 \quad(51)$ & $16 \quad(41)$ & 19 (49) & $24 \quad(53)$ & 29 & (64) \\
\hline $80-100$ & $8 \quad(21)$ & $12 \quad(31)$ & $14 \quad(36)$ & 12 (31) & 13 (29) & 13 & (29) \\
\hline$<80$ & $7 \quad(18)$ & 7 (18) & $9 \quad(23)$ & $8 \quad(20)$ & $8 \quad(18)$ & 3 & (7) \\
\hline
\end{tabular}

Source: UNEPI's Reports, Ministry of Health, Uganda 
Table 3

Districts change in immunisation coverage between the two rounds of NIDs for 1996-1998

\begin{tabular}{|c|c|c|c|c|c|c|}
\hline \multirow[t]{2}{*}{ Districts with } & \multicolumn{2}{|c|}{1996} & \multicolumn{2}{|c|}{1997} & \multicolumn{2}{|c|}{1998} \\
\hline & No. & $(\%)$ & No. & $(\%)$ & No. & $(\%)$ \\
\hline Increase & 10 & 26 & $(18)$ & $(46)$ & 40 & (89) \\
\hline Decrease & 29 & (74) & 21 & (54) & 5 & (11) \\
\hline Increase $>$ or $=5 \%$ & 7 & (18) & 11 & (28) & 30 & (67) \\
\hline Increase $>$ or $=10 \%$ & 3 & (8) & 5 & (13) & 20 & (44) \\
\hline
\end{tabular}

Source: UNEPI's reports, Ministry of Health, Uganda

Table 4

NIDs coverage in Uganda by districts in 1998

\begin{tabular}{|c|c|c|c|c|}
\hline District & Target population & $\begin{array}{l}\text { Coverage } \\
\text { round one }\end{array}$ & $\begin{array}{l}\text { Coverage } \\
\text { round two }\end{array}$ & $\begin{array}{c}\text { Percentage } \\
\text { change }\end{array}$ \\
\hline Kampala & 169500 & 78.4 & 82.2 & 5.8 \\
\hline Bushenyi & 142700 & 74.9 & 99.2 & 14.3 \\
\hline Mubende & 115200 & 71.5 & 91.9 & 20.4 \\
\hline Luwero & 92000 & 66.7 & 76.7 & 10.0 \\
\hline A-Mpigi & 216300 & 65.9 & 73.5 & 7.6 \\
\hline A-Rakai & 86500 & 48.5 & 87.9 & 39.4 \\
\hline A-Ntungamo & 74200 & 47.4 & 89.6 & 42.2 \\
\hline NA_Sembabule & 31300 & 43.9 & 72.2 & 28.3 \\
\hline A-Kapchorwa & 28000 & 145.6 & 149.8 & 4.2 \\
\hline NA-Bugiri & 53800 & 138.8 & 160.4 & 21.6 \\
\hline $\mathrm{N}$ Adjumani & 21500 & 137.5 & 94.1 & -43.4 \\
\hline A _Pallisa & 86600 & 134.7 & 148.0 & 13.3 \\
\hline A_Soroti & 77700 & 131.5 & 127.0 & -4.5 \\
\hline Kibaale & 49600 & 129.8 & 142.9 & 13.1 \\
\hline A-Kumi & 64300 & 127.7 & 147.7 & 20 \\
\hline A-Apac & 105000 & 127.5 & 135.1 & 7.6 \\
\hline A-Kotido & 46300 & 125.4 & 127.0 & 1.6 \\
\hline Lira & 119500 & 124.6 & 117.2 & -7.4 \\
\hline A-Mbale & 174600 & 119.8 & 131.7 & 11.9 \\
\hline A-Iganga & 167200 & 119.6 & 120.1 & 0.5 \\
\hline A-Busia & 39300 & 116.0 & 139.0 & 23 \\
\hline Tororo & 96500 & 114.2 & 108.1 & -6.1 \\
\hline $\mathrm{NA}_{-K a t a k w i}$ & 43400 & 111.9 & 120.3 & 8.4 \\
\hline A-Masindi & 66800 & 109.7 & 115.1 & 5.4 \\
\hline A-Kasese & 82100 & 109.1 & 113.4 & 4.3 \\
\hline Моyo & 19400 & 108.2 & 123.3 & 15.1 \\
\hline Jinja & 74100 & 107.1 & 124.9 & 17.8 \\
\hline A-Nebbi & 79000 & 106.2 & 123.1 & 16.9 \\
\hline Gulu & 85100 & 105.3 & 119.1 & 13.8 \\
\hline N-Nakasongola & 22600 & 104.8 & 108.5 & 3.7 \\
\hline Arua & 153900 & 102.1 & 111.6 & 9.5 \\
\hline Moroto & 50000 & 101.0 & 101.6 & 0.6 \\
\hline A-Kamuli & 118000 & 99.9 & 102.0 & 2.1 \\
\hline Hoima & 49900 & 97.1 & 101.2 & 4.1 \\
\hline A_Kabale & 112200 & 96.3 & 96.8 & 0.5 \\
\hline A_ Kitgum & 90300 & 95.6 & 101.0 & 5.4 \\
\hline Mukono & 205200 & 94.8 & 95.1 & 0.3 \\
\hline A $_{\text {-Kabarole }}$ & 174500 & 92.1 & 102.4 & 10.3 \\
\hline Rukungiri & 101500 & -90.9 & 100.6 & 9.7 \\
\hline Masaka & 164600 & 90.0 & 88.8 & -1.2 \\
\hline Bundibugyo & 31300 & 89.9 & 97.3 & 7.4 \\
\hline A-Kisoro & 48200 & 89.8 & 99.6 & 9.8 \\
\hline Kiboga & 33000 & 88.1 & 112.3 & 24.2 \\
\hline A-Mbarara & 190500 & 81.4 & 99.3 & 17.9 \\
\hline Kalangala & 3600 & 81.3 & 97.5 & 16.2 \\
\hline
\end{tabular}

A-implemented vitamin A supplementation in second round

$\mathrm{N}_{\text {-new district }}$ 
In order to reflect the effects of the new districts on the immunisation coverage, further analysis was done for these new districts and the results compared with the national average and with the old districts for the year 1998. The new districts were: Nakasongola Katakwi Adjumani, Busia, Sembabule, and Bugiri. In fact, the coverage in these districts was higher than the national average and in the old districts by all parameters: first round NIDs 1998 (111.3\% for new districts versus the national average of $97.7 \%$ and versus $97 \%$ for the old districts ), second round (122.9\% for new districts versus the national average of $106.9 \%$ and versus $106.0 \%$ for the old districts) and increase between round two and round one $(11.6 \%$ for the new districts versus the national average of $9.2 \%$ and versus $9 \%$ for the old districts).

In order to gauge the effect of vitamin supplementation on NIDs coverage for the year 1998, further analysis was done comparing coverage with districts that implemented vitamin A supplementation with the national average and with those that did not implement vitamin A. The districts that implemented vitamin A supplementation were: Apac, Bugiri, Busia, Iganga, Kabale, Kabarole, Kamuli, Kapchorwa, Kasese, Katakwi, Kisoro, Kitgum, Kotido, Kumi, Masindi, Mbale, Mbarara Mpigi, Nebbi, Ntungamo, Pallisa, Rakai, Sembabule, Soroti. Those districts that implemented vitamin had higher coverage for the first round (100.1\% as compared to a national average of 97.7 $\%$ and to $94.5 \%$ of those that did not implement vitamin A). For the second round, those districts that implemented vitamin A had a coverage of $111.5 \%$ compared to $106.9 \%$ for the whole nation and to $101.2 \%$ for the districts that did not include vitamin A. Regarding the increase in coverage between round one and round two of NIDs 1998 those that implemented vitamin A had an increase of $10.4 \%$ as compared to the national increase of $9.2 \%$ and of $6.7 \%$ for those that did not implement vitamin A.

\section{DISCUSSION}

Before interpreting these data, it is necessary to explain why the coverage for some districts and the national average is in some instances more than $100 \%$. There could be several reasons for this. Firstly, some of the children immunised were above five years. Although, the recording form distinguished those below five years and those above five years, it is possible that some children over five years were recorded as below five years either because the parents/guardians were not sure of the age or because the parents/guardians lied about the age so as to have the children immunised. Secondly, some districts, especially in northern Uganda, harbour many refugees and internally displaced persons and these could have swelled the number children eligible for immunisation. Thirdly, parents from neighbouring districts of Sudan, Kenya and the Democratic Republic of Congo could have brought their children to Uganda for immunisation. Finally, district population could have been under-projected in general and the targeted population for immunisation in particular. It is possible that the growth rate of some districts may be higher or lower than the national average of $2.5 \%(3)$.

While interpreting these data it is important to consider all possible measures that may have increased the immunisation coverage during the second round of NIDS 1998. Such measures may have included increased social mobilisation, child caretakers' enthusiasm, introduction of vitamin A supplementation and introduction of NIDs cards.

The increased enthusiasm and social mobilisation is unlikely to have increased the national coverage during the second round of NIDs 1998 for two reasons. Firstly, the coverage during the first round of NIDs 1998 was higher than in 1996 as well as in 1997, so it is unlikely that there could have been more mobilisation for the second round of NIDs in 1998 as compared to that of 1996 and 1997. Secondly, increased social mobilisation was expected in the new districts as way of legitimising their existence and to show that they could implement health initiatives successfully. Although the level in coverage between rounds two and one was higher than the national average and those of the old districts, the proportion of target population in these new districts was very small (5.2\% of national population) and, therefore, their overall effect on national coverage would subsequently be very small indeed.

Another factor likely to have increased the immunisation coverage is the vitamin A supplementation implemented during the second round of 1998 NIDs. Anecdotal evidence showed that vitamin A was highly valued by parents/ guardians, especially in central Uganda. Indeed the districts that implemented vitamin A, achieved a higher increase that the national average as compared to those that did not. However, since those that did not implement vitamin A also achieved a $6.7 \%$ increase in coverage, it can be assumed that even among those that implemented vitamin A supplementation some of the observed coverage increases may not be wholy attributed to vitamin A.

The effect of immunisation cards on the NIDs is more complex to interpret. Since all the districts issued out cards at the same time, it may not be safely stated that the cards primarily contributed to the increased coverage. It would have been desirable to draw a comparison between a group of districts that did not introduce cards with those that used the cards to be certain that the observed increase in NIDs coverage was attributable to the introduction of NIDs cards. There is, however, evidence from the current study and from previous studies $(4,5)$ that cards may indeed increase immunisation coverage and attendance for other preventive services. In this study there was an increase of immunisation coverage after introduction of cards. This increase was higher in districts that administered vitamin A supplementation alongside NIDs. Moreover, it was possible to reach the $100 \%$ national NIDs coverage for the first time ever in both the districts that administered vitamin A and in those that did not. Furthermore, there was a marked improvement in poorly performing districts after the introduction of the cards. 
NIDs cards could have acted in several ways to improve the immunisation coverage. Firstly, families could have feared that the authorities could apprehend them if they did not have the NIDs cards. Before the introduction of cards, there was no way of distinguishing the immunised from the un-immunised. Secondly, some churches, mosques, schools, and government health units request for immunisation cards before baptisms, school registration or before giving treatment. Thus it is an advantage to possess the card and hence the rush to get immunised and obtain the NIDs cards. Cards are also regarded as official documents that indicate that a good caring family complies with government initiatives. Thus a family or mother who has a vaccination card has some elevated self-esteem and prestige(5). Ante-natal care (ANC) attendance data from Uganda shows that the majority of women attending these clinics do so to obtain ANC cards whose possession serves as a precautionary measure against harassment by health workers should there be need for institutional delivery(4). Furthermore, some mothers attend routine immunisation clinics to get the Road-to Health card, which facilitates easy access during visits for curative services in government health units and often leads to the women being complimented and not abused by health workers $(4,5)$.

Before the introduction of NIDs cards, those who campaigned against the NIDs claim the following: "you see the government has something to hide and that is why you are no given cards when you attend for NIDs". "This shows that if anything wrong happens then there is no evidence that you were actually immunised and you cannot sue the goverment" (5). So providing NIDs cards could have counteracted this reasoning. Other people also used to say that: " even the government was not serious about NIDs", Why is it that when one attends for routine immunisation, for ante-natal, or pays graduated tax, he or she is given a ticket or card. Why not for NIDs(5)? So the issue of NIDs cards could have signalled that the government was serious this time round.

Anecdotal evidence before the NIDs cards were introduced showed that immunisation posts that recorded children's names did in fact, achieve much higher coverages than those that did not. Thus registration and issue of cards could also have reduced what some groups described as "laziness" in previous research work(5), thus encouraging parents to come for NIDs.

In conclusion, it is probable that due to the foregoing reasons, among others, the introduction of NIDs immunisation cards could have been responsible for the increased NIDs coverage in Uganda. It is recommended that NIDs card should continue to be used. Furthermore, these data suggest that the addition of popular programmes such as vitamin A supplementation may increase NIDs coverage.

\section{REFERENCES}

1. Gounder, C. The progress of the polio eradication initiative: what prospects for eradicating measles. Hlth Policy and Planning 1998; 13: 212-233.

2. Ministry of Health National coverage for first round and second round of National Immunisation Days, 1996 and 1997. Uganda National Expanded Programme on Immunisation, Ministry of Health Entebbe, Uganda.

3. Uganda Demographic and Health Survey. Ministry of Planning and Economic Development, Kampala Uganda 1995.

4. Kaguna, A.B. and Nuwaha, F. Factors influencing choice of delivery sites in Rakai district of Uganda. Soc. Sci. Med. 2000; 50:203-213.

5. Nuwaha, F., Mulindwa, G., Kabwongyera, E. and Barenzi, J. Factors responsible for low immunisation coverage of National Immunisation Days in Bushenyi district of Uganda. 1999; (in press). Trop. Med. Int. Hlth. 